\title{
PENGELOLAAN ADAPTIF PEMANFAATAN BUAH HITAM \\ (Haplolobus monticola Blumea) ETNIS WANDAMEN-PAPUA (Adaptive Management Utilization of Black Fruit (Haplolobus monticola Blumea) Ethnic Wandamen-Papua)
}

\author{
Antoni Ungirwalu*1, San Afri Awang', Ahmad Maryudi² dan Priyono Suryanto \\ ${ }^{1}$ Fakultas Kehutanan Universitas Papua, Jl. Gunung Salju Amban, Manokwari 98314. \\ ${ }^{2}$ Fakultas Kehutanan Universitas Gadjah Mada, Bulaksumur, Yogyakarta 55281.
}

*Penulis korespondensi. Tel: 081344123400. Email: antoni.ungirwalu@ yahoo.com.

\author{
Diterima: 16 November 2015
}

Disetujui: 7 Maret 2016

\begin{abstract}
Abstrak
Kajian ekologi budaya bertujuan untuk mendeskripsikan karakteristik lingkungan ekologi dan sosial-budaya masyarakat adat etnis Wandamen-Papua dalam mengkonstruksi pengelolaan sumberdaya alam adaptif untuk pemanfaatan buah hitam (Haplolobus monticola Blumea) sebagai salah satu dasar pertimbangan penting bagi penyusunan kebijakan pengelolaan hutan berkelanjutan di Papua. Pengelolaan sumberdaya alam adaptif buah hitam dipengaruhi oleh karakteristik sosial budaya etnis Wandamen yang memiliki pola kepemilikan dan penguasaan sumber daya alam (SDA) meliputi: tanah, perairan, dan hutan. Masing-masing dalam lingkungan wilayah adatnya yang bersifat komunal, dibentuk dari pola kekerabatan dengan tipe Iroquois dan diwariskan melalui sistem patrilineal. Struktur sosial etnis WandamenPapua bersifat askriptif dalam kemajemukan sosial-budaya (banyak sub-etnis), namun dalam perkembangnnya hanya sub-etnis Wamesa yang memiliki kearifan lokal tentang pemanfaatan tumbuhan buah hitam yang dijumpai pada tipologi habitat ekologi, meliputi: hutan alam, hutan sekunder, dan kebun-pekarangan. Konstruksi etnoekologi pemanfaatan SDA buah hitam bagi etnis Wandamen memiliki enam wujud, yaitu sebagai sumberdaya lokal, pengetahuan lokal, nilai lokal, teknologi lokal, mekanisme pengembilan keputusan lokal, serta solidaritas kelompok lokal.
\end{abstract}

Kata kunci: etnoekologi, ekologi budaya, sumberdaya alam, berkelanjutan, buah hitam.

\begin{abstract}
Study of cultural ecology aimed to describe the characteristics of the ecological factors and socio-culture of indigenous ethnic of Wandamen-Papua in constructing the adaptive management of natural resources for the use of black fruit (Haplolobus monticola Blumea) that is necessary for policy-making of the sustainable forest management in Papua. Adaptive management of natural resource of black fruits depend mainly on the characteristics of social culture of Wandamen ethnic. The management have a pattern of ownership and control of Natural Resources (NR) i.e.: soil, water, and forests. They are the customary territory on the community that are from the pattern of kinship with the type of Iroquois and passed through the patrilineal system. Social structure of Wandamen-Papua ethnic is ascriptive in the plurality of socio-cultural (micro sub-ethnic). However, only sub-ethnic Wamesa patterns have local knowledge regarding the use of plants black fruits found on the typology of habitat ecology such as natural forest, secondary forest and home garden. The construction of ethno ecology utilization of black fruit as natural resource by Wandamen ethnic can be described in six types namely local resource, local knowledge, local value, local technology, procedure to make decision and solidarity of local community.
\end{abstract}

Keywords: ethnoecology, cultural ecology, natural resources, sustainable, black fruit.

\section{PENDAHULUAN}

Terdapat kecenderungan global untuk mengakomodasi inisiatif pengelolaan yang adaptif oleh masyarakat yang sudah secara turun-temurun menguasai dan memelihara hutan (Kobbail, 2011). Sebelumnya nilai dan bentuk kearifan lokal kurang mendapat pengakuan (recognition) dan penghargaan. Akibatnya, selain model pengelolaan hutan yang diterapkan saat ini belum mampu mengakomodasi kepentingan masyarakat lokal sehingga bentuk kearifan lokal mereka berangsurangsur semakin dilupakan (Awang dkk., 2007). Hobs (2009) menekankan pentingnya untuk mempertimbangkan restorasi dalam kerangka multidisiplin yang menyumbang tidak hanya untuk kepentingan ekologi tetapi juga konteks sejarah dan budaya. Untuk itu diperlukan evaluasi terhadap bentuk-bentuk pengelolaan hutan kemasyarakatan dengan mengkaji apakah program pemanfaatan hasil hutan yang dapat dilaksanakan telah menghasilkan apa yang telah dijanjikan (Maryudi dkk., 2012). 
Komponen utama pengelolaan adaptif sumberdaya alam adalah sistem masyarakat, sistem lingkungan dan sistem kebudayaaan sebagai satu kesatuan utuh yang tidak terpisahkan satu dengan lainnya. Masyarakat tidak terlepas dari lingkungan dimana dia tinggal, terdapat hubungan sistem budaya membentuk tipologi masyarakat berdasarkan klasifikasi-klasifikasi karakteristik lingkungan. Hubungan sebab-akibat (in causal terms) antara kebudayaan dan lingkungan sumberdaya hutan selalu dikaitkan dengan peradaban budaya manusia melalui proses interaksi pemanfaatan hutan secara berkelanjutan (Naveh, 2007; Musacchio, 2009; Nurhadi dkk., 2012; Fatem dkk., 2014). Sejak dahulu lingkungan hutan memiliki multi fungsi penting bagi masyarakat di sekitarnya dan dijadikan tempat berinteraksi untuk memenuhi kebutuhan dasar. Teori ini pertama kali diungkapkan secara utuh oleh Steward pada tahun 1955 dalam bukunya Theory of Culture Change, bahwa proses masyarakat mengadaptasi budaya dipengaruhi oleh penyesuaian dasar yang dilakukan manusia dalam menggunakan lingkungannya.

Ekosistem hutan bila ditinjau dari segi struktur dasarnya atas dari dua komponen utama, yaitu komponen abiotik dan biotik. Pola interaksi komponen biotik dengan lingkungannya dilakukan melalui tahap-tahap adaptasi biologis yang menyebabkan berbagai jenis organisme hidup memiliki kondisi dan keadaan biologis yang selaras dengan keadaan habitatnya. Proses ini dilakukan agar setiap komponen biotik dalam ekosistem mampu beradaptasi dengan lingkungan. Demikian pula dengan keberadaan manusia, harus terus menjaga hubungan yang adaptif dengan lingkungannya agar tetap dapat mempertahankan kehidupannya.

Model adaptif pemanfaatan secara tradisional oleh masyarakat etnis Wandamen-Papua juga dijumpai pada tumbuhan hutan jenis Buah hitam (Haplolobus monticola) atau yang secara lokal dikenal dengan sebutan "Pi Airawi". Etnis Wandamen-Papua dalam kehidupan subsitemnya menjadikan buah hitam sebagai salah satu sumber pangan alternatif. Berdasarkan kajian ekologibudaya sejauh ini masih sangat terbatas dalam melihat hubungan budaya masyarakat etnis Wandamen-Papua dengan lingkungan sumberdaya alam tentang pemanfaatan buah hitam secara adaptif. Oleh karena itu kajian ekologi budaya yang dilakukan bertujuan untuk memperoleh informasi tentang karakteristik lingkungan sosial-budaya masyarakat adat etnis Wandamen, serta mengkonstruksi kembali pengelolaan adaptif etnoekologi pemanfaatan buah hitam Etnis Wandamen di Papua. Diharapkan hasil kajian ini akan bermanfaat untuk menambah khasanah pengetahuan tentang karakter sosial-budaya komunitas etnis di Papua sekaligus menjembatani diskursus proses pemanfaatan adaptif sumberdaya alam dalam regulasi kebijakan di Papua guna terwujudnya hutan lestari dan masyarakat sejahtera.

\section{METODE PENELITIAN}

\section{Waktu dan Lokasi}

Penelitian ini dilaksanakan pada bulan Agustus 2010, Juli 2013 dan Oktober 2015. Lokasi kampung/desa ditentukan secara purposive di 3 (tiga) Distrik, yaitu distrik Wasior, distrik Wondiboi dan distrik Rasiey. Ke-4 lokasi penelitian adalah kampung Rado, kampung Dotir, kampung Kaibi dan kampung Tandia. Penelitian kualitatif ini difokuskan untuk mencari penjelasan sosiologis dari interaksi sosial-budaya dan sistem pengetahuan lokal pemanfaatan buah hitam menggunakan metode etnografi kognitif dengan mengumpulkan data primer dan sekunder dari etnografi etnis Wandamen dan ekologi buah hitam.

\section{Prosedur}

Sumber data diperoleh secara langsung dari informasi masyarakat yang berada di lokasi penelitian. Pengumpulan data dilakukan terhadap responden yang memenuhi syarat utama sebagai pelaku yang terlibat aktif dalam proses pemanfataan tumbuhan buah hitam. Pemilihan informan sebagai responden kunci dilaksanakan dengan pengambilan contoh secara sengaja (purposive sampling) menggunakan model "snowball". Model kajian etnoekologi didekati melalui penggunaan metode etnografi yang dikembangkan Spradley (2006) serta kajian ekologi habitat Buah hitam melalui tahap pengamatan terlibat, wawancara dan studi literatur.

\section{Analisis}

Data etnografi masyarakat adat etnis Wondama dan ekologi buah hitam yang terkumpul diklasifikasi dan dideskripsikan secara holistik-integratif melalui pendekatan interpretatif research dan basic reseach, dianalisis dan ditafsirkan secara kualitatif dari sudut pandang konstruksi sosial dari sistem pengetahuan sosial-budaya tentang pemanfaatan Buah hitam.

\section{HASIL DAN PEMBAHASAN}

\section{Ekologi Habitat Buah hitam}

Berdasarkan taksonominya tumbuhan buah hitam merupakan salah satu jenis tumbuhan dari famili Burceraceae. Famili Burceraceae dikelompokan sebagai tumbuhan jenis kenarikenarian yang banyak ditemukan pada kawasan Malesiana. Penyebaran famili Burceraceae hampir 


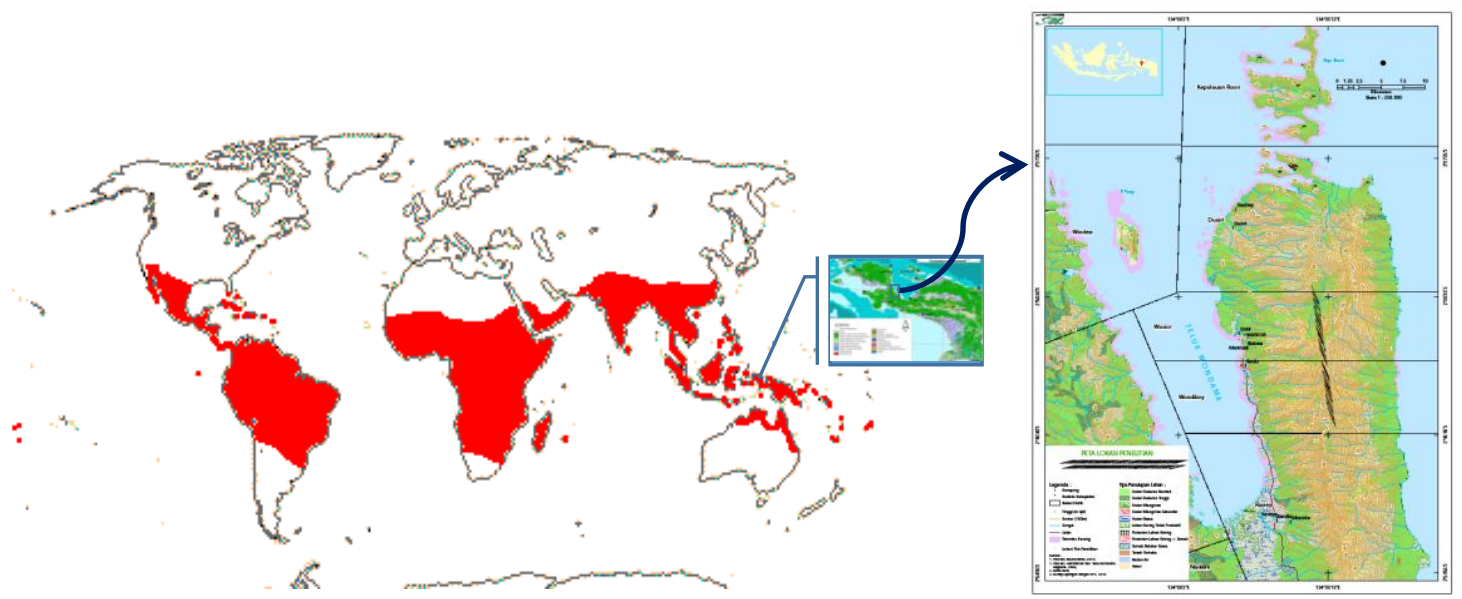

Gambar 1. Penyebaran Burceracea di dunia (warna merah) dan lokasi penelitian.

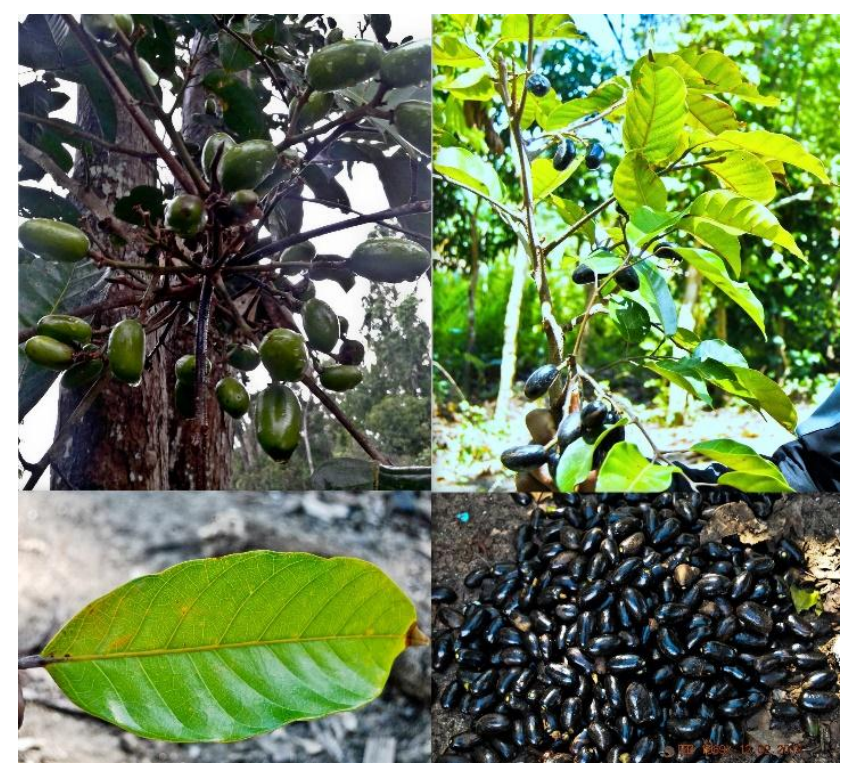

Gambar 2. Buah hitam (Haplolobus monticola).

Tabel 1. Identifikasi pemanfaatan tumbuhan buah hitam di Papua.

\begin{tabular}{lll}
\hline Nama Lokal & Nama Ilmiah & Asal \\
\hline Wom & Haplolobus floribunda & Yapen \\
Wom & Haplolobus floribunda & Numfor \\
* buah hitam & Haplolobus lanceolatus & Nabire \\
* buah hitam & Haplolobus monticola.** & Manokwari \\
Pi Airawi & Haplolobus monticola.** & Wandamen \\
Inggabui & Haplolobus variegta & Wandamen \\
Niase & Haplolobus acumintaus & Wandamen \\
\hline \multicolumn{2}{c}{ Ket: * Masyarakat menyebutkan dalam bahasa Indonesia. } \\
** Dapat dikonsumsi. Sumber: Data primer, 2015.
\end{tabular}

dijumpai pada sebagian besar daerah tropis dan sub tropis (Gambar 1).

Jumlah anggota genus Haplolobus cukup banyak dan beberapa di antaranya diperkirakan terdapat di Papua dan Maluku. Hasil kajian dan deskripsi buah hitam yang dimanfaatkan oleh masyarakat etnis Wandemen dikelompokkan dalam jenis Haplolobus monticola (Gambar 2). Jenis tumbuhan buah hitam yang dimanfaatkan oleh masyarakat di Papua ternyata berbeda menurut habitat asal. Hasil identifikasi tumbuhan buah hitam dapat dilihat pada Tabel 1.

Pemanfaatan tumbuhan buah hitam tidak hanya sebatas pemenuhan kebutuhan subsisten sebagai sumber bahan makanan. Sejarah pemanfaatannya yang panjang mengandung nilai religius dan tradisi adat bagi etnis Wandamen. Secara epistimologis, hasil kajian wawancara tentang sejarah buah hitam, berasal dari bahasa Wamesa dengan sebutan"P $i$ Airawi" diartikan sebagai benda/buah (berwarna hitam untuk buah yang sudah matang) yang berada di atas pohon. Buah hitam dan hutan memiliki nilai sosial-budaya yang berhubungan erat dengan sistem kepercayaan adat okultuisme. Okultuisme etnis Wandamen percaya bahwa roh/makhluk hidup yang berada di hutan dan berhubungan erat dengan keberadaan tumbuhan hutan.

Manfaat sosial-budaya dari habitat ekologi tumbuhan lokal buah hitam turut memainkan peran penting bagi proses pengetahuan pengelolaan SDA

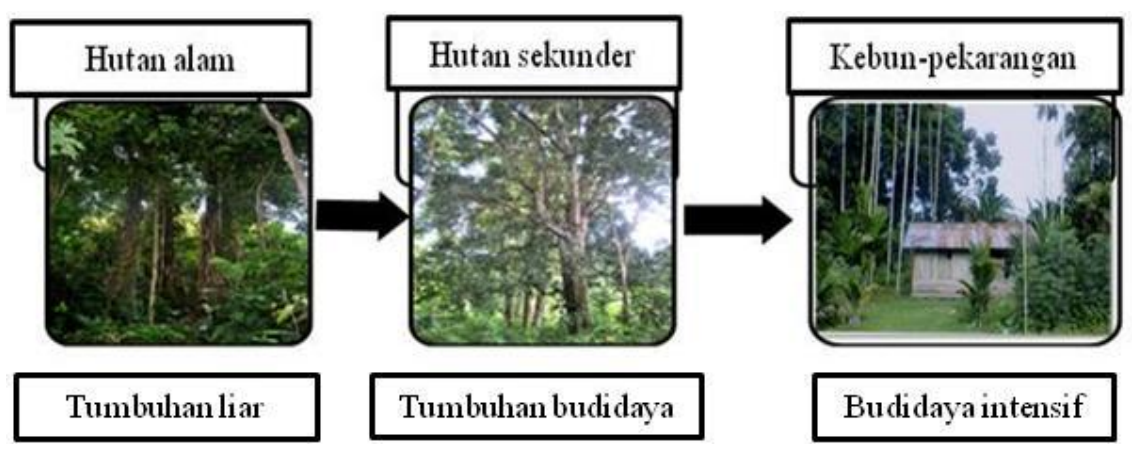

Gambar 3. Tipologi perubahan habitat dan pemanfaatan buah hitam Etnis Wandamen-Papua. 
Tabel 2. Fisiografis ekologi buah hitam.

\begin{tabular}{lccccc}
\hline \multicolumn{1}{c}{ Lokasi } & Pohon & $\begin{array}{c}\text { Ketinggian } \\
(\mathrm{m}) \mathrm{dpl}\end{array}$ & $\begin{array}{c}\text { Topografi } \\
(\%)\end{array}$ & $\begin{array}{c}\text { Jarak sumber Air } \\
(\mathrm{m})\end{array}$ & $\begin{array}{c}\text { Jarak pemukiman } \\
(\mathrm{m})\end{array}$ \\
\hline Kebun-pekarangan & $3-5$ & $7-14$ & $0-5$ & $5-30$ & $5-150$ \\
Hutan sekunder & $5-8$ & $1-47$ & $0-15$ & $5-50$ & $30-200$ \\
Hutan primer & 5 & $135-218$ & $5-25$ & $20-100$ & $3.000-10.000$ \\
\hline
\end{tabular}

Sumber: Data primer, 2015.

oleh masyarakat adat etnis Wandamen. Proses ini merupakan awal dari proses sistem pengetahuan masyarakat etnis Wandamen dalam konteks penguasaan SDA melalui pola penyebaran benih dan pembudidayaan tumbuhan buah hitam. Secara fisiografis ekologi domestikasi awal buah hitam dilakukan etnis Wandamen di tiga lokasi utama yaitu: hutan primer/alam, hutan sekunder dan kebunpekarangan (Gambar 3). Karakter fisiografis ekologi buah hitam dideskripsikan pada Tabel 2.

Ciri mencolok fisiografis habitat tumbuhan buah hitam adalah berkelompok (merumpun) dengan jumlah 3-8 pohon pada luasan tempat tumbuh berukuran rata-rata $20 \times 30$ meter. Letak lokasi zona terletak pada jarak yang bervariasi. Untuk jarak terjauh dijumpai pada lokasi hutan alam yang berjarak antara 3-10 km dari lokasi pemukiman. Penyebarannya dijumpai pada ketinggian 1-218 m dpl dengan bentuk topografi yang bervariasi dari $0-5 \%$ (daerah dataran rendah) sampai dengan 5-25\% (daerah bukit bergelombang). Bentuk satuan morfologi untuk daerah dataran rendah adalah terdiri dari satuan batuan malihan, satuan batu lanau, endapan pantai dan satuan alluvium. Pola aliran yang berkembang adalah dendritik dengan lembah berbentuk huruf "U" yang mencerminkan bahwa tahap erosi sudah mencapai tingkat dewasa. Sementara untuk daerah bergelombang sebagaian besar terdiri dari satuan batu gamping, batuan malihan, batu pasir, batu lumpur dan batu lanau dengan pola aliran dan erosi yang berkembang adalah dendritik-sub dendritik. Jarak lokasi habitat tumbuh tumbuhan buah hitam dan aliran sungai (DAS) relatif cukup dekat 5-100 $\mathrm{m}$.

Perubahan tipologi habitat dari hutan primer ke hutan sekunder menggambarkan bentuk perubahan evolusi pola adaptasi dari aktivitas proses sosial pembentukan mata pencaharian etnis Wandamen yaitu keadaan transisi dari pola sistem berburu dan peramu menuju sistem perladangan berpindah (budidaya). Proses perubahan habitat tumbuhan buah hitam yang asalnya dari tumbuhan liar di hutan alam menjadi tumbuhan yang dibudidayakan pada kawasan hutan sekunder dan kebun-pekarangan. Proses ini merupakan wujud respon adaptif etnis Wandamen dalam memanfaatkan potensi sumberdaya hutan yang tersedia.

\section{Karakteristik Sosial Budaya Etnis Wandamen- Papua}

Pemakaian kata masyarakat adat dalam etnis Wandamen adalah untuk menonjolkan sebagian kecil dari komunitas dimana mereka lebih terikat oleh lingkungan tempat beraktivitas. Sedangkan komunitas masyarakat adat yang dimaksud adalah penduduk asli Papua dari etnis Wandamen yang hidup pada wilayah sosial-budaya di daerah Teluk Wondama yang ditandai oleh derajat hubungan sosial (sistem kekerabatan) yang saling terikat satu sama lainnya.

Etnis Wandamen memiliki identitas etnografi sebagai penciri. Penciri yang sama juga dijumpai pada kebanyakan etnis Papua lain yang bermukim di pesisir pantai. Karakter fisik etnis Wandamen tergolong dalam ras Melanosoit/Melanesia. Beberapa ahli antropologi dan etnografi berpendapat bahwa ras Melanesia memiliki karakter yang khas dengan kepribadian keras dan gesit. Wallace dalam catatan ekspedisinya tahun 1869 mencatat bahwa ras Papua memiliki ciri yang sama dengan penduduk Kei dan Aru di kepulauan Maluku. Masyarakat ini memiliki badan yang lebih tinggi dari penduduk ras Melayu, muka lonjong, hidung besar agak bengkok dan mancung, kulit coklat tua kadang kehitaman, dan memiliki rambut keras, kering dan keriting. Semua kebudayaan etnis Wandamen dapat dijelaskan secara sosio-phsikologikal, karena karakter yang dimiliki merupakan wujud dari fikiran. Perilaku timbul sebagai wujud reaksi mental phsikologis yang terangsang oleh keadaan lingkungan (Poerwanto, 2005; Setiadi dkk., 2006; Marshad, 2011).

Secara askriptif etnis Wandamen memiliki kemajemukan sosial-budaya. Komunitasnya memiliki sistem kekerabatan tipe Iroquois yaitu sistem yang mengklasifikasikan anggota kerabat saudara sepupu paralel dengan istilah yang sama dengan saudara kandung. Juga untuk menyebut istilah yang sama untuk ayah maupun sesama saudara laki ayah dan saudara laki ibu. Dalam komunitas etnis Wandamen, terdiri atas banyak anak suku atau sub etnis yang disebut dengan micro-etnic. Sub etnis tersebut tercermin dari perbedaan bahasa, struktur organisasi, sistem kepemimpinan adat, sistem kepercayaan dan sistem mata pencaharian. Perbedaan unsur-unsur budaya tersebut ditentukan 
oleh keragaman karakter ekologi lingkungan dimana sub etnis itu bermukim.

Sistem kepercayaan tradisonal etnis Wandamen adalah Okultisme yaitu kepercayaan yang mengabungkan ananisme dan dinamisme. Hingga kini sistem kepercayaan tradisonal sudah banyak ditinggalkan sejak etnis Wandamen sejak memeluk agama Kristen, namun dalam menghadapi persoalan-persoalan mendasar yang menimpa kehidupan manusia seperti tertimpa kecelakaan, sakit dan kematian, masih mencari jawabannya melalui kepercayaan lama mereka. Asal-usul keberadaan etnis Wandamen tidak terlepas dari sistem kepercayaan tradisional yang diperoleh dari cerita Mitos yang diturunkan dari generasi ke generasi. Dalam perspektif budaya etnis Wandamen, terdapat tiga kategori mitos, yaitu: Topunusara, atau cerita legenda asal-usul manusia, tempat kediaman dan kejadian-kejadian yang dipercaya kebenarannya. Kavo arami, merupakan cerita rakyat bersifat fiksi yang diceritakan kepada anak-anak pada waktu malam sebagai penghantar tidur. Kavo Vipidiar, merupakan pengungkapan kata-kata yang tidak dapat diucapkan secara sembarangan menyangkut adat-istiadat etnis Wandamen, karena dapat mendatangkan bencana.

Sistem kepemimpinan tradisional etnis Wandamen adalah kepemimpinan campuran antara sistem kepemimpinan Raja dan Ondoafi, dan Pria berwibawa (Bigman). Terdapat dua tipe penguasaan dan pemanfaatan SDA di dalam struktur sosial etnis Wandamen, yaitu kepemilikan bersama (komunal) dan kepemilikan individu. Sistem pewarian tanah adat, sumberdaya alam dan sistem pengambilan keputusan berada pada kaum pria keturunan tertua. Hak kepemilikan dan penguasaan tanah/hutan adat yang bersifat komunal berada di tangan kepala suku atau kepala klen yang kemudian membaginya kepada anggota suku atau klen dengan luasan tertentu. Kepala suku atau kepala klen/marga juga menentukan dan mengatur cara pemanfaatan tanah/hutan untuk pemenuhan kebutuhan hidup anggota suku atau klen/marganya.

Sebagai komunitas masyarakat adat, etnis Wandamen yang terdiri atas: individu, marga (keret), dan klen (sub-etnis). Hak kepemilikan adat dan penguasaan tanah, hutan, sungai dan laut dalam wilayah hukum adat diwariskan kepada anak lelaki tertua yang nantinya akan menggantikan bapaknya menjadi ketua dari klen bersangkutan. Ketua keret berfungsi mengatur pembagian dan pemanfaatan lahan dan sumberdaya alamnya, termasuk hasil hutan yang terdapat di dalamnya untuk pemenuhan kebutuhan hidup subsisten maupun untuk komersial. Bentuk-bentuk pemanfaatan secara tradisionil untuk pemenuhan kebutuhan subsisten seperti meramu (ekstraksi hasil hutan, berburu dan berladang berpindah dilakukan dalam bagian-bagian wilayah yang menjadi bagian kekuasaannya. Sistem pembagian wilayah kepemilikan dan penguasaan sumberdaya alam bagi etnis Wandamen sekaligus dijadikan sebagai petunjuk status.

Lingkungan alam (physical environment), memberikan pengaruh terhadap penentuan lokasi pemukiman dan mata pencaharian bagi masyarakat etnis Wandamen. Komunitas ini menempati 3 (tiga) zona ekologi, yaitu: zona ekologi rawa, daerah pantai dan muara sungai, zona ekologi daerah pantai, dan zona ekologi kaki-kaki gunung serta lembahlembah kecil. Mansoben (1995) mengelompokan etnis Wandamen sebagai masyarakt yang bermata pencaharian utama sebagai peladang berpindahpindah dan meramu sagu, sementara mata pencaharian sampingan mereka adalah menangkap ikan di sungai atau laut.

Sub-etnis Wamesa merupakan anggota etnis Wandamen yang dominan dijumpai menempati lingkungan biogeofisik daerah dataran rendah yang strategis di pinggiran pantai dan muara-muara sungai. Kondisi tersebut memberikan keuntungan tersendiri bagi kelompok sub-etnis Wamesa sehingga lebih maju dan berkembang dibandingkan dengan sub etnis pada lingkungan pulau dan lembahpegunungan yang memiliki pembatas daerah sebagai daerah terpencil dan sulit dijangkau. Selain mudah dijangkau, lokasi ini dijadikan sebagai pusat kegiatan adat dan pemerintahan sejak dari dulu. Dalam kajian penelitian etnoekologi ini, difokuskan pada sub-etnis Wamesa yang berada di Distrik Wasior, Distrik Wondiboi dan Distrik Rasiei. Dari beberapa komunitas sub-etnis yang ada di Wandamen, sub-etnis Wamesa yang sejak dahulu memiliki pengetahuan lokal dalam memanfaatkan tumbuhan lokal buah hitam.

\section{Pemanfaatan Sumberdaya Alam di Kabupaten Teluk Wondama}

Proses pemanfaatan sumberdaya hutan secara berkelanjutan dari generasi ke generasi memiliki keterkaitan hubungan dengan sistem sosial dalam suatu kelompok masyarakat dengan keberadaan fungsi kawasan hutannya. Jika dipandang dari aspek hutan di wilayah Kabupaten Teluk Wondama berdasarkan data tahun 2012 adalah seluas 411.764 ha. Hutan Wondama telah ditetapkan berdasarkan 3 (tiga) fungsi utama yaitu fungsi lindung, fungsi produksi dan fungsi konservasi, yang diimplementasi dari UU Pokok Kehutanan No. 41 Tahun 1999. Luas peruntukkan kawasan hutan di Kabupaten Teluk Wondama digunakan sebagai kawasan hutan konservasi, yaitu seluas 94.377,29 ha $(22,9 \%)$, selanjutnya difungsikan peruntukannya 
bagi kawasan hutan produksi seluas $242.711,95$ ha (34\%), hutan lindung $74.674,83$ ha $(18,1 \%)$. Peran negara sangat dominan dalam menentukan kebijakan dan regulasi, sehingga mulai dari penguasaan, peruntukan dan pemanfaatan di bidang kehutanan semuanya oleh negara dengan terjebak dalam cara berpikir parsial 'menguasai' itu sama dengan 'memiliki' bukan 'mengatur' dengan bijak. Hal ini nampak terlihat dengan adanya program dan kebijakan pengelolaan sumberdaya alam di Wondama lebih dominan difungsikan bagi produksi hasil kayu komersial (timber extraction) dan bentuk pengelolaan kawasannya difragmentasikan ke dalam berbagai fungsi-fungsi hutan yang sempit. Kondisi tersebut bertolak belakang dengan pola hubungan pemanfaatan adaptif yang sudah ada dan diterapkan oleh etnis Wandamen.

Jauh sebelum kebijakan penetapan peruntukan kawasan hutan oleh pemerintah, masyarakat etnis Wandamen telah melakukan interaksi dan adaptasi secara intens dengan lingkungan hutan di sekitarnya. Hutan oleh komunitas masyarakat etnis Wandamen dijadikan tempat berinteraksi untuk memenuhi kebutuhan subsistennya dengan cara meramu, berladang, berburu dan melakukan aktivitas budaya dan religinya. Oleh karena itu seharusnya kajian kebijakan terhadap pemanfaatan hasil hutan secara langsung dikatakan sebagai kunci bagi pengembangan masyarakat lokal saat ini (Bhattacharya dan Basnyat, 2003; Charnley dan Poe,
2007; Maryudi dkk., 2012). Dalam memenuhi kebutuhan hidup sehari-hari masyarakat adat Wandamen masih bergantung pada SDA sekitarnya. Masyarakat etnis Wandamen memanfaatkan lingkungan biofisik hutan untuk memenuhi kebutuhan pangan, sandang, maupun perumahan sesuai dengan kebutuhan subsistennya sebagaimana dideskripsikan dalam Tabel 3.

Tabel 3 menunjukkan bahwa hutan memiliki fungsi ganda (muti fungsi) bagi etnis Wandamen karena hasil hutan berupa jenis-jenis tumbuhan hutan memiliki fungsi secara langsung maupun tidak langsung bagi pemenuhan kebutuhan hidup etnis Wandamen. Manfaat sumberdaya hutan bagi masyarakat adat etnis Wandamen, terdiri atas manfaat nyata yang terukur (tangible) berupa hasil hutan kayu, hasil hutan non kayu, serta manfaat tidak terukur (intangible) berupa manfaat perlindungan lingkungan, keragaman genetik dan nilai-nilai adat. Hal yang sama dapat dijumpai pada masyarakat etnis di Papua secara umum. Penelitian etnobiologi Fatem dkk (2015) membuktikan bahwa interaksi masyarakat dalam pemanfaatan SDA oleh Suku Meyah di Wilayah Pantai Utara Manokwari guna memenuhi kebutuhan sehari-hari. Dalam lingkungan masyarakat adat etnis Papua tumbuhan hutan dapat dijadikan sebagai bagian dari antrophogeography (Fischer) sekaligus mendukung teori land ethic (Leopold), dimana pemanfaatan tumbuhan hutan dapat dikombinasikan dalam pandangan ekologi dan

Tabel 3. Etnoekologi pemanfaatan tumbuhan oleh masyarakat adat etnis Wandamen.

\begin{tabular}{|c|c|c|c|c|}
\hline Fungsi & Jenis & Nama lokal & Nama Ilmiah & Famili \\
\hline \multirow[t]{6}{*}{ Sumber bahan makanan } & Pohon & Anannga/Ananggemo & Metroxylon sago & Aracaceae \\
\hline & Pohon & Pi Airawi & Haplobus monticola & Burceraceae \\
\hline & Pohon & Tawan & Pometia pinnata & Sapindaceae \\
\hline & Pohon & Langsat & Langsium domesticum & Meliaceae. \\
\hline & Pohon & Cempedak & Arthocharpus integer & Moraceae \\
\hline & Pohon & Manggis & Garcinia mangostana & Clusiaceae \\
\hline \multirow[t]{7}{*}{ Sumber obat-obatan } & Pohon & Goenae & Alstonia scolaris & Apocynaceae \\
\hline & Pohon & Kasiae & Ficus stipulosa & Moraceae \\
\hline & Pohon & Paraei & Soneratia alba & Sonneratiaceae \\
\hline & Pohon & Karor & Barringtonia asiatica & Lecythidaceae \\
\hline & Liana & Piriau Wemas & Dioscore $\mathrm{sp}$ & Dioscorreaceae \\
\hline & Liana & Awen wawi & Centrosema pubescens & Papilionaceae \\
\hline & Liana & Remandau & Piper bacatum & Piperaceae \\
\hline \multirow[t]{4}{*}{ Sumber bahan bangunan } & Pohon & Paraei & Rhizophora apiculata & Rhizoporaceae \\
\hline & Pohon & Anannga & Metroxylon sago & Aracaceae \\
\hline & Pohon & Tawan & Pometia pinnata & Sapindaceae \\
\hline & Pohon & Ron & Instia Bijuga & Caesalpinaceae \\
\hline \multirow{2}{*}{$\begin{array}{l}\text { Sumber bahan pembuatan } \\
\text { perahu }\end{array}$} & Pohon & Kinem & Octomeles sumatrana & Datiscaceae \\
\hline & Pohon & Baay & Paraserianthes falcataria & Mimosaceae \\
\hline \multirow[t]{3}{*}{ Sumber pendapatan tunai } & Pohon & Masoi & Cryptocarya spp. & Lauraceae \\
\hline & Pohon & gaharu & Aquilaria spp. & Thymelaceae \\
\hline & Pohon & Kayu Manis & Cinnamomum burmannii & Lauraceae \\
\hline Sumber & Liana & Posandakai & Holopegia sp & Cannaceae \\
\hline \multirow[t]{2}{*}{ perlengkapan sehari-hari } & Liana & Kasuparauw & Pisonia sp & Nyctaginaceae \\
\hline & Liana & Waiwiria & Merremia peltata & Convolvulaceae \\
\hline
\end{tabular}

Sumber: Data primer, 2015. 
pertanian (Awang, 2006). Secara ideal inti ekologi adalah bahwa manusia harus menyesuaikan diri dengan sistem alam dan harus membolehkan lingkungan hutan hadir pada pikiran masyarakat sendiri. Konsep ini didasarkan pada pengakuan saling ketergantungan dan sinergi erat antara masyarakat dan hutan (Stevens, 1997; Maryudi dkk., 2012). Dalam pemahaman ini interaksi tersebut bersifat proses kreatif, yang perlu dipahami terutama berasal dari manusia terhadap ekosistemnya sebagai faktor determinan yang dalam proses perkembangannnya sangat rentan terhadap perubahan suatu kebudayaan (Mansoben, 1995).

\section{Konstruksi Etnoekologi Pemanfaatan Buah hitam}

Etnoekologi pemanfaatan SDA buah hitam bagi etnis Wandamen memiliki 6 (enam) wujud, yaitu sebagai sumber daya lokal, pengetahuan lokal, nilai lokal, keterampilan lokal, mekanisme pengambilan keputusan lokal, dan solidaritas kelompok lokal.

\section{Sumberdaya lokal}

Selain buah hitam, tanaman hutan yang dimanfaatkan sebagai sumber makanan adalah sagu (Metroxylon spp.) sebagai sumber bahan makanan pokok, matoa (Pometia pinnata), langsat (Langsium domesticum), cempedak (Arthocharpus integer) dan manggis hutan (Garcinia mangostana) adalah jenis tumbuhan bahan makanan alternatif. Studi etnobotani yang dilakukan Powell (1976), sebanyak 650 jenis tumbuhan yang meliputi 134 famili dan 378 genus telah berhasil teridentifikasi dan dapat dimanfaatkan manusia. Jenis tumbuhan yang dimanfaatkan sebagai bahan makanan terdapat kurang lebih 231 jenis, dengan bagian-bagian yang dimanfaatkan adalah pucuk, daun, batang, buah, biji, bunga, umbi dan akar. Hasil kajian dari jenis tumbuhan yang telah berhasil diidentifikasi sebagai penghasil bahan makanan, dominan berasal dari biji, pati dan buah-buah hutan, dimana pada masa lalunya jenis tumbuhan ini telah dijadikan sebagai sumber makanan pokok maupun sebagai sumber makanan tambahan bagi sebagian besar etnis yang tersebar di wilayah Papua dan Papua New Guinea. Buah hitam (H. monticola) merupakan jenis tumbuhan lokal yang dimanfaatkan secara intensif sebagai sumber makanan tambahan sementara sagu (Metroxylon spp) dan umbi-umbian merupakan makanan pokok etnis Wandamen yang telah dimanfaatakan sejak para leluhurnya telah menjadi sebuah kebudayaan dan terus dipertahankan hingga kini. Hal yang sama dilaporkan Klooster (2002) bahwa intensifikasi pemanfaatan sumberdaya hutan termasuk hutan secara sosial lingkungan dilakukan secara berkelanjutan oleh masyarakat adat.

\section{Pengetahuan lokal}

Pemanfaatan buah hitam oleh etnis Wandamen merupakan hasil dari proses adaptasi para leluhur melalui pengamatan secara tidak langsung terhadap burung-burung pemakan buah. Proses pemanfaatan buah hitam dikategorikan kedalam simbol kognitif (Ungirwalu, 2012). Proses pengetahuan lokal (informal) yang berkaitan dengan penjelasanpenjelasan akal sehat tentang pemanfaatan buah hitam oleh para leluhur untuk menterjemahkan sesuatu dari luar ke dalam otaknya untuk dipakai dan difungsikan sehingga memberi keyakinan bahwa buah hitam pada awalnya dapat dikonsumsi secara langsung karena tidak berbahaya (beracun). Selain itu buah hitam ternyata memiliki rasa yang enak (tekstur daging yang tipis dengan rasa sedikit manis agak sepat).

Proses tindakan yang berasal dari lingkungan alam selanjutnya ditransfer dalam keseharian masyarakat sebagai wujud kenyataan sosial yang ada. Kenyataan keseharian kehidupan masyarakat adat etnis Wandamen membentuk pola tindakan yang stabil karena pemanfaatan tumbuhan ini telah menjadi tradisi yang dilakukan oleh para leluhur, dari generasi ke generasi sehingga melembaga sebagai pengetahuan yang bersifat informal. Pendekatan partisipatif kehutanan masyarakat dianggap menghasilkan peningkatan manfaat bagi masyarakat lokal dengan pengetahuan lokal yang dimiliki sehingga mendorong kepatuhan sukarela dalam memicu inovasi dan memberikan kontribusi bagi pemanfaatan hutan secara berkelanjutan yang terdiri atas manfaat ekonomi, sosial dan ekologi (Kellert dkk., 2000).

\section{Nilai lokal}

Etnis Wandamen termasuk dalam kelompok kekerabatan tipe Iroquois dan berdasarkan sistem pewarisan nilai budaya Patrilineal. Terdapat hubungan erat antara proses pewarisan pengetahuan lokal etnis Wandamen dengan hubungan kekerabatan dan sistem pewarisan. Belajar melalui kebiasaan mengikuti orang tua ke hutan sejak kecil merupakan pendidikan informal yang sangat berharga bagi etnis Wandamen, tidak hanya untuk mengetahui nilai kegunaannya tetapi juga untuk dapat mewariskan nilai sosial (kebersamaan dan gotong-royong) kepada generasi berikut. Keberadaan buah hitam yang mengandung nilai kegunaan dan nilai budaya, kemudian diturunkan kepada generasi berikutnya sebagai simbol terhadap hak waris dalam tatanan adat etnis Wandamen. 
Koentjaraningrat (1990), mengatakan bahwa sistem nilai budaya adalah suatu rangkaian konsepsi abstrak yang hidup dalam alam pikiran sebagaian besar masyarakat mengenai apa yang dianggap penting dan berharga, tetapi juga mengenai apa yang dianggap remeh dan tidak berharga. Sistem nilai budaya merupakan tingkatan yang paling abstrak dari adat. Sistem nilai budaya terdiri atas konsepsikonsepsi yang hidup dalam alam pikiran sebagaian besar masyarakat. Karena itu, suatu sistem nilaibudaya biasanya berfungsi sebagai pedoman tertinggi bagi tingkah laku manusia. Kegunaan, kepuasan, dan kesenangan adalah kata lain yang berarti mengandung nilai-nilai yang benar dan dapat diterima oleh akal sehat.

\section{Keterampilan lokal}

Keterampilan lokal etnis Wandamen dapat ditemukan melalui beberapa tahapan proses pemanfaat buah hitam yang dimulai dari pra panen, panen dan pasca panen. Dalam tahapan pra penen dijumpai proses keterampilan sebagai pengetahun lokal etnis Wandamen dalam perlindungan tumbuhan buah hitam sebagai tindakan konservasi dari gangguan hama pemakan buah hitam seperti burung, kelelawar dan hewan pengerat lainnya. Keterampilan untuk menyelamatkan buah hitam dari serangan hewan pemakan buah terbentuk karena tumbuhan ini memiliki buah yang berharga dan nilai sosial budaya tinggi. Berdasarkan hal itu maka masyarakat berupaya agar buah hitam yang telah masak panen, tidak habis dimakan hama burung atau hewan pengerat lain. Masyarakat etnis Wandamen berhasil menciptakan teknologi untuk menghalau hewan-hewan pemakan buah hitam. Teknologi tersebut berupa peralatan sederhana yang terbuat dari bahan-bahan lokal dan bersifat ramah lingkungan yang berfungsi untuk menghasilkan bunyi dalam menghalau hewan pemakan buah. Peralatan dimaksud antara lain Apiaimi, yaitu lembaran kayu matoa (Pometia spp.) yang dirangkai secara berseri. Lembaran ini bila dipukul akan mengeluarkan suara nyaring sehingga dapat menakuti hewan pemakan buah hitam. Kabareru, merupakan anyaman dari daun pandan (Pandanus spp.) berbentuk layang-layang. Posisi Kabareru digantung pada sebilah bambu yang telah dipotong pendek dan diberi tali untuk tetap bergerak melayang mengikuti arah angin. Wujud kearifan lokal masyarakat dalam melindungi buah hitam membentuk kondisi ekologi yang relatif lebih stabil dengan keberadaan populasi satwa liar tetap terjaga dalam membentuk keseimbangan alam (homeostatis).

Pada tahapan pemanenan, dilakukan semacam ritual adat (doa-doa singkat) ketika akan memanjat atau pada saat turun kembali. Hal ini bertujuan agar diberi kelancaran sekaligus menghindari ancaman kehilangan hasil panen buah. Masih tergambar dalam pandangan masyarakat bahwa selama proses pemanenan buah hitam, seluruh tahapan pelaksaaannya benar-benar diusahakan mengikuti kebiasaan yang sudah dilakukan oleh para leluhurnya terutama oleh para pemimpin marga/keret/klen dalam etnis Wandamen. Jika dilihat dari persepsi terhadap sesama bahwa perilaku individu dalam komunitas etnis Wandamen dipengaruhi oleh sistem struktur sosial, dimana pemimpin dalam kelompok (marga/klen) selalu menjadi panutan. Hubungan horizontal dalam komunitas terhadap sikap dan tindakan menjadi pedoman utama bagi generasi di dalamnya.

Pada tahapan pasca panen dijumpai keterampilan masyarakat etnis Wandamen dalam pembuatan dan pembakaran/pengasapan campuran buah hitam dan sagu buah hitam atau yang disebut dengan "Beriam Tereu". Proses inovasi mencampurkan daging buah hitam dengan sagu yang merupakan salah satu hasil makanan pokok etnis Wandamen, kemudian memunculkan kemampuan (skill) baru bagi individu untuk diproses menjadi produk pemanfaatan lanjutan dari buah hitam. Pada awalnya keterampilan lokal etnis Wandamen hanya cukup dan mampu memenuhi kebutuhan keluarganya masing-masing atau disebut dengan ekonomi subsisten. Keterampilan lokal ini juga bersifat keterampilan hidup (life skill), sehingga keterampilan ini sangat tergantung kepada kondisi geografi tempat dimana masyarakat itu tinggal, dimana sejauh ini masih mengandalan hutan, sungai dan laut sebagai sumber penyedia bahan bakunya. Fakta empiris ini didukung pula oleh Leopold dengan konsep teori land ethic menyatakan bahwa secara ideal inti ekologi adalah bahwa manusia harus menyesuaikan diri dengan sistem alam dan harus membolehkan lingkungan hutan hadir pada pikiran masyarakat sendiri (Awang, 2006).

\section{Mekanisme pengambilan keputusan lokal}

Salah satu mekanisme pengambilan keputusan lokal yang terjadi dalam kelompok masyarakat etnis Wandamen adalah dalam peristiwa jamuan (pesta adat) buah hitam dan proses pembuatan "Beriam Tereu". Selain sebagai bentuk simbol solidaritas di dalam kelompok komunitasnya, jamuan dalam makan buah hitam maupun proses pembakaran "Beriam Tereu" digunakan juga sebagai bagian proses rekonsolidasi keluarga (marga/keret/klen) untuk membicarakan permasalahan yang terjadi seperti perkelahian atau pertengkaran antar keluarga, rencana pembayaran denda karena tuntutan keluarga lain atau rencana pembayaran mas kawin dalam 
pesta perkawinan. Prosedur pengambilan keputusan ini dilakukan dengan cara bermusyawarah untuk mencapai mufakat dalam menentukan suatu sikap apa yang akan diambil sebagai keputusan akhir dari kelompok masyarakat tersebut. Mekanisme ini didukung pula oleh premis dasar bahwa peran yang penting dari masyarakat dalam pengambilan keputusan akan mempengaruhi lingkungan hutan di sekitarnya dan dapat mencapai peningkatan sosial ekonomi kesejahteraan dan keberlanjutan ekologi (Shrestha, 2005).

\section{Solidaritas kelompok lokal}

Ikatan komunal yang mempersatukan suatu masyarakat terletak pada solideritas lokal. Setiap masyarakat mempunyai media untuk mengikat warganya melalui berbagai ritual adat. Dalam masyarakat adat etnis Wandamen terdapat sikap gotong-royong yang merupakan suatu sistem pengerahan tenaga tambahan dari luar kalangan keluarga (marga/keret/klen) untuk mengisi kekurangan tenaga pada lingkaran suatu aktivitas produksi seperti kegiatan tokok sagu, pembuatan kebun, dan juga pembuatan "Beriam Tereu" ataupun pada saat pesta-pesta adat yang dilakukan (pesta perkawinan, bayar mas kawin, maupun syukuran). Bantuan tenaga yang diberikan oleh keret/klen ataupun dari luar keret/klen itu sendiri merupakan bentuk simbol solideritas kelompok yang sudah tertanam sejak dahulu. Sebagai bentuk kompensasi dan penghormatan berupa tanda terimakasih bagi mereka yang membantu, maka biasanya marga/keret/klen yang dibantu akan melakukan jamuan makan bersama.

Pada saat panen buah hitam sebagai tradisi yang dilakukan oleh masyarakat pemilik pohon dengan mengundang para kerabat dan keluarga terdekat dari marga/keret/klen untuk bersama melaksanakan ritual makan bersama (perjamuan). Bentuk dalam jamuan tersebut adalah menyajikan buah hitam segar yang dapat dimakan secara langsung ataupun akan disajikan bersamaaan dengan makanan hasil kebun atau hasil berburu, seperti umbi-umbian, sagu, daging ataupun ikan, ataupun jamuan berupa olahan buah hitam atau "Beriam tereu". Jamuan makan tidak terlepas dari adopsi nilai-nilai agama yang dianut masyarakat Wandamen sebagai simbol kebersamaan, rasa penghormatan dan kasih sayang diantara mereka. Hal yang sama juga berlaku pada saat proses pembakaran "Beriam Tereu" dengan melibatkan banyak kerabat atau keluarga terdekat. Masingmasing anggota masyarakat tersebut saling memberi dan menerima sesuai dengan kemampuannya secara spontan tanpa adanya suatu paksaan. Di dalam pengeloaan hutan oleh masyarakat lokal, pemanfaatan secara langsung diharapkan memainkan peran penting dalam pengambilan keputusan bersama membuat prosedur dan pelaksanaan kegiatan kehutanan

\section{KESIMPULAN}

Manajemen adaptif adalah cara yang direkomendasikan untuk melanjutkan pengelolaan ekosistem dan penggunaan sumber daya alam, terutama dalam konteks pengelolaan keberlanjutan yang dilakukan oleh Etnis Wandamen-Papua. Secara konseptual, manajemen adaptif pemanfaatan buah hitam dengan belajar dari pengetahuan tradisional etnis Wandamen di masa lalu yang dapat digunakan untuk memperbaiki perencanaan dan pengelolaan hutan lestari di masa depan.

Etnoekologi pemanfaatan sumber daya hutan oleh etnis Wandamen terhadap pemanfaatan tumbuhan lokal buah hitam memiliki sifat keunggulan adaptabilitas yang tinggi terhadap lingkungan dalam proses interaksi dan adaptasi. Komunitas masyarakat suku besar atau etnis Wandamen dikelompokan dalam dua anak suku yaitu sub etnis Wamesa (90\%) dan sub etnis Soug (10\%). Sistem kepercayaan tradisional yang diperoleh dari cerita mitos yang diturunkan dari generasi ke generasi turut berpengaruh terhadap proses pemanfaatan SDA. Pola kepemilikan dan penguasaan SDA meliputi tanah, perairan, dan hutan, termasuk di dalamnya tumbuhan buah hitam dalam lingkungan wilayah adat etnis Wandamen bersifat komunal dengan struktur kekerabatan tipe Iroquois yang diwariskan melalui sistem patrilineal. Sementara sistem kepemimpinan tradisional adalah sistem kepemimpinan campuran antara sistem kepemimpinan Raja dan Ondoafi, dan Pria berwibawa (Bigman). Sifat askriptif kemajemukan sosial-budaya dalam tatanan mikro-etnis namun hanya sub-etnis Wamesa yang memiliki pengetahuan tentang pemanfaatan buah hitam dalam kehidupan kesehariannya.

Konstruksi etnoekologi pemanfaatan SDA buah hitam bagi etnis Wandamen memiliki 6 (enam) wujud, yaitu sebagai sumberdaya lokal, pengetahuan lokal, nilai lokal, teknologi lokal, mekanisme pengembilan keputusan lokal, serta solidaritas kelompok lokal. Dari penelitian ini dapat disarankan agar pengelolaan adaptif etnis Wandamen dalam pemanfaatan buah hitam perlu dipertahankan, dikembangkan dan diadopsi dalam pembuatan kebijakan pengelolaan hutan berkelanjutan di Papua.

\section{UCAPAN TERIMAKASIH}

Prof. Dr. Charlie D. Hetubun, S.Hut., M.Si., FLS; Krisma Lekitoo, S.Hut., M.Sc., O. P. Matani, 
S.Hut, M.Sc dan Ezrom Baturinding, S.Hut., M,Sc., buat kontribusinya hingga tulisan ini dapat dilengkapi dengan data pendukung dan gambar yang komperhensif.

\section{DAFTAR PUSTAKA}

Awang, S.A., 2006. Sosiologi Pengetahuan Deforestrasi. Konstruksi Sosial dan Perlawanan. Debut Press, Yogyakarta.

Awang, S.A., Wiyono, E.B., dan Sadiyo, S., 2007. Unit Manajemen Hutan Rakyat: Proses Konstruksi Pengetahuan Lokal. Awang (Ed). Banyumili Art Network, Yogyakarta.

Bhattacharya A.K., and Basnyat, B., 2003. Empowering People Through Joint Forest Management: A Study from Madhya Pradesh (India). International Forestry Review, 5(4):370-378.

Charnley, S., dan Poe, M.R. 2007. Community Forestry in Theory and Practice: Where are We Now?. Annual Review of Anthropology, 36:301-336.

Fatem, S., Peday, M. H. dan Yowei, R. N., 2014. Ethno-Biological Notes on The Meyah Tribe From The Northern Part of Manokwari, West Papua. Jurnal Manusia dan Lingkungan, 21(1):121-127.

Hobs, R., 2009. Woodland Restoration in Scotland: Ecology, History, Culture, Economics, Politics and Change. Journal of Environmental Management, 90:857-2865

Kellert, S.R., Mehta, J.N., Ebbin, S.A., dan Lichtenfeld, L.L., 2000. Community Natural Resource Management: Promise, Rhetoric, and Reality. Society and Natural Resources, 13(8):705-715

Klooster, D.J., 2002. Toward Adaptive Community Forest Management: Integrating Local Forest Knowledge with Scientific Forestry. Jurnals Economic Geography, 78(1):43-70.

Kluckhohn, F.R., dan Strodtbeck, F.L., 1961. Variations in Value Orientations. Harper and Row, New York.

Kobbail, A.A.R, 2011. Natural Forest Reserves Management From Local Perspectives: A Challenge for Developing a Participatory Forest Management Model. International Journal of Social Forestry, 4(1):32-62.

Koentjaraningrat, R.M., 1990. Pokok-pokok Antropologi Sosial. PT Dian Rakyat. Jakarta.
Mansoben, J.R, 1995. Sistem Politik Tradisional di Рариа. Lembaga Ilmu Pengetahuan Indonesia (LIPI) dan Leiden University. Jakarta.

Marshad, D., 2011. Alfred Russel Wallace, Kiprah dan Karyanya sebagi Ilmuan Sosial. LIPPI Press. Jakarta.

Maryudi, A., Devkota R., Schusser, C., Yufanyi, C., Salla, M., Aurenhammer, H., Rotchanaphatharawit, R., dan Krott, M., 2012. Back to Basics: Considerations in Evaluating the Outcomes of Community Forestry. Forest Policy and Economics, 14(1):1-5.

Musacchio, L.R., 2009. The Ecology and Culture of Landscape Sustainability: Emerging Knowledge and Innavation in Landscape Research and Practice. Landscape Ecology, 24:989-992.

Naveh, Z., 2007. Landscape ecology and sustainability. Landscape Ecology 22:14371440.

Nurhadi, A., Setiawan, B., dan Baiquni., 2012. Kearifan Lingkungan dalam Perencanaan dan Pengelolaan Hutan Wonosari Kecamatan Ngawen Kabupaten Gunungkidul. Jurnal Manusia dan Lingkungan, 19(3):226-237.

Powell, J. M., 1976. Ethnobotany. In K. Paijmans (Ed.). New Guinea Vegetation. The Australian National University Press. Canberra, p 106170.

Poerwanto, H., 2005. Kebudayaan dan Lingkungan. Pustaka Pelajar Offset. Yogyakarta.

Setiadi, E.M., Hakam, K.A., dan Effendi, R., 2006. Ilmu Sosial dan Budaya Dasar. Ed 2. Kencana, Jakarta

Shrestha, K.K., 2005. Collective Action and Equity in Nepalese Community Forestry. $\mathrm{PhD}$ Thesis, School of Geosciences, The University of Sydney, Sydney.

Spradley, J.P., 2006. Metoda Etnografi (Edisi kedua). Tiara Wacana. Yogyakarta.

Stevens, S., 1997. Conservation Through Cultural survival Island Press, Washington, D.C

Steward, S., 1955. Theory of Culture Change; The Methodology of Multilinear Evolution . Urbana: University of Illinois Press. USA.

Ungirwalu, A., 2012. Interaksi Simbolik Etnis Wandamen-Papua dalam Pemanfaatan Tumbuhan Buah hitam (Haplolobus monticola). Jurnal Kehutanan Tropika, $1(1): 25-34$. 